\section{Institute of Physics}

THE annual general meeting of the Institute of Physics was held on Tuesday, May 19. After election of the officers and completion of the panel of the Board, it was announced that the following would take office on October 1, 1936 : President, Prof. A. Fowler ; Vice-President, Mr. F. Twyman; Honorary Treasurer, Major C. E. S. Phillips; Honorary Secretary, Prof. J. A. Crowther; New Members of the Board, Colonel K. W. E. Edgeumbe and Prof, R. Whiddington. The annual Report for the year 1935 which was adopted at the meeting shows that membership has continued to increase and that the high standard required for corporate membership has been maintained. The total membership at the end of the year was 822. The first Industrial Physics Conference to be held in Great Britain took place in Manchester in March 1935, and the attendance was nearly 550. The subject of the Conference was "Vacuum Devices in Research and Industry", and an exhibition of instruments, apparatus and books cognate to the subject was arranged and was open to the public. Some 3,500 people visited the exhibition. A Midland Local Section was inaugurated in November, the towns covered being Birmingham, Leicester, Nottingham and Rugby. The Report shows that the scheme for the training and certificating of laboratory assistants has developed satisfactorily and 21 certificates were issued during the year. The Institute's services in placing employers in touch with physicists seeking permanent posts and with consultants were in constant demand throughout the year. The circulation of the Journal of Scientific Instruments increased during the year, both on account of the commencement of its distribution to 'associates' without extra payment and on account of sales to non-members.

\section{The Education of Naval Architects}

$A T$ the recent meeting of the Institution of Naval Architects, Mr. L. Woollard gave an account of the methods of training naval architects in Great Britain to-day in Admiralty establishments, at the universities and at the various technical colleges. As is well known, the Admiralty more than a century ago took the lead in technical education, and the work of the schools in the dockyards, at South Kensington and Greenwich, has been reviewed at various times by Sir William White, Sir William Smith and Sir Arthur Johns. To-day, however, there are courses for degrees in naval architecture at the Universities of Glasgow, Durham and Liverpool, while there are no fewer than seventeen technical schools or colleges in England and Scotland where courses can be followed for the National Certificates in Naval Architecture. These certificates are awarded by a Joint Committee of the Institution of Naval Architects and the Worshipful Company of Shipwrights, in conjunction with the Board of Education or Scottish Education Department. Mr. Woollard gives particulars of the courses followed at the R.N. College, Greenwich, and elsewhere, the scholarships open to students and a list of papers and articles in the education of naval architects. When referring to Admiralty training, he says that experience has shown that candidates have more difficulty in satisfying the examiners in mathematics than in the other subjects, and students weak in mathematics find great difficulty in keeping pace with the courses at Greenwich.

\section{Uniformity as the Gauge of Quality}

IN a paper read to the Institution of Electrical Engineers on May 1, Mr. C. C. Paterson pointed out that there is always a tendency to judge a manufactured product by its showing one desirable feature rather than from its uniformity. He said that with certain exceptions, such as the laws of gravity, there is a remarkable absence of uniformity throughout Nature. There is a tendency to admire extremes, such as the tallest mountain or the longest river. This explains why there is a certain distrust in the pursuit of uniformity. The engineer is rather apt to take it for granted. Much attention is paid to classtesting, but the same effort is not made to ensure that every product is up to the level of the class tested. In the case of electric boiling plates, for example, if the supply voltage is 6 per cent low the consumption of energy compared with the heat developed is increased 14 per cent. Variations such as these are superimposed on the manufacturers' permissible limits of variation now called 'tolerances'. Fifteen years ago, the manufacture of glass was largely a matter of rule of thumb methods, with the result that in making lamps about 150 bulbs were used for every 100 lamps. When an effort was made to obtain glass of uniform quality with the desired characteristics, only 104 bulbs were used for each 100 lamps produced. In the early days of dry battery manufacture, great stress was laid on individual output. With the growing use of multicellular batteries, where failure of any unit meant failure of the whole battery, attention was concentrated on securing uniformity, with the result that the failures now are of the order of five in a million. In conclusion, Mr. Paterson dwelt on the importance of using frequency curves when assessing the deviation of products from the standard. Instead of using tolerances, it would be much better to adopt the coefficient of variation or the standard variation from the frequency curve by the method used by statisticians.

\section{Influence Lines}

In the analysis of bearns and girders it is possible by the method of influence lines to simplify the process of determination of the stresses due to the passage of a system of rolling loads. In such cases the preparation of diagrams of maximum bending moment and shear force is usually a laborious matter; whereas it is eminently simple to construct a bending moment influence diagram which, for a particular section, will show the bending moment at that section due to a load of one ton placed at any point in the beam. For the given section the one diagram serves each and every load, but while the use of influence lines is generally referred to in structural engineering textbooks, the special technique required in their applica- 